\title{
A CIDADANIA PARTICIPATIVA NO SISTEMA ÚNICO DE ASSISTÊNCIA SOCIAL
}

\author{
J. PAGANINI e R. S. VIEIRA* \\ Universidade do Extremo Sul Catarinense \\ prof.reginaldovieira@gmail.com*
}

Artigo submetido em novembro/2015 e aceito em dezembro/2015

DOI: $10.15628 /$ holos.2015.3687

\section{RESUMO}

Este estudo teve por objetivo analisar a cidadania participativa no Sistema Único de Assistência Social, através de seus mecanismos legitimadores, tendo como marco a Constituição da República Federativa do Brasil de 1988 e a regulamentação da Lei Orgânica da Assistência Social. A escolha do tema se deu pelo reconhecimento de as políticas públicas realizadas pelo Estado serem fiscalizadas e deliberadas pela sociedade, ocasionando um avanço em termos de cidadania participativa. Utilizou-se o método de abordagem dedutivo, adotando a abordagem qualitativa e o procedimento monográfico. As técnicas envolveram pesquisa documental-legal e bibliográfica. Os resultados comprovaram que o Sistema único de Assistência Social possui instrumentos para a realização da cidadania participativa, por meio dos conselhos e conferências, na qualidade de espaços de controle social, que devem ser reinventados quotidianamente pela sociedade, sob pena de se converterem apenas em estruturas cartoriais de cumprimento de requisitos formais para a transferência de recursos públicos, fundados em práticas patrimonialistas e clientelistas.

PALAVRAS-CHAVE: Cidadania participativa, Controle social, Conselhos, Conferência, Sistema Único de Assistência Social.

\section{THE PARTICIPATORY CITIZENSHIP IN THE UNIFIED SOCIAL ASSISTANCE}

\begin{abstract}
This study aimed to analyze participatory citizenship in the Unified Social Assistance, through its legitimating mechanisms, taking as a landmark the Constitution of the Federative of Brazil 1988 and the regulations of the Organic Law of Social Assistance. The topic of choice was the recognition of the public policies implemented by the state, monitored and determined by society, causing a breakthrough in terms of participatory citizenship. We used the deductive, qualitative and the monographic
\end{abstract}

procedure. The techniques involved documentary-legal and bibliographic research. The results showed that the Unified Social Assistance has instruments for the realization of participatory citizenship, through councils and conferences, as spaces social control, which must be reinvented every day by society, se as not to become only notary structures of compliance with formal requirements for the transfer of public resources, founded in patrimonial and clientelistic practices.

KEYWORDS: Participatory citizenship, Social control, Councils, Conference, Unified Social Assistance. 


\section{INTRODUÇÃO}

O termo cidadania foi construído historicamente. O seu conceito variou conforme o contexto político e econômico de cada sociedade, ou seja, se na antiguidade esta era exercida diretamente, na modernidade ela tornou-se representada, retirando da sociedade a sua capacidade participativa.

No Estado Democrático de Direito, a cidadania contém uma interpretação mais abrangente, no sentido de alcançar tanto o direito ao voto (representativo) quanto a participação nas esferas sociais (participativo), sendo que no Brasil visualizou-se tais instrumentos no próprio texto da Constituição da República Federativa do Brasil de 1988, em seu artigo 1ำ, parágrafo único, quando expressa: "Todo o poder emana do povo, que o exerce por meio de representantes eleitos ou diretamente, nos termos desta Constituição" (BRASIL, 1988).

No que diz respeito à assistência social, a CRFB/1988, assim como a Lei Orgânica de Assistência Social (LOAS) promulgada em 1993, estabeleceram diretrizes para uma cidadania participativa, prevendo a participação da sociedade no controle e na fiscalização de suas ações.

Neste contexto, o cidadão poderá exigir do Estado a execução da política pública de assistência social, tendo em vista entendê-la não como um favor, mas como um direito de cidadania. Para tanto, foi fundamental a elaboração a Política Nacional de Assistência Social (PNAS) em setembro de 2004, implantando no Brasil o Sistema Único de Assistência Social (SUAS) e consequentemente concretizando as diretrizes da LOAS.

Entretanto, em que pese a consolidação da PNAS no Brasil, faz-se necessária uma reflexão acerca das possibilidades de controle e de participação pela sociedade de seus programas e serviços, já que eles são ofertados aos usuários/cidadãos do SUAS em todo o âmbito nacional.

Portanto, este estudo é desenvolvido em três partes. Na primeira, aborda-se a concepção de cidadania em seu contexto histórico. A segunda parte descreve a cidadania no Brasil, focando o seu aspecto participativo. Por fim, será analisada a concretização da cidadania participativa na assistência social, destacando-se a importância da atuação da Sociedade na formação e na execução das ações do SUAS.

Foi utilizado na pesquisa o método dedutivo, por meio da abordagem qualitativa e do procedimento monográfico, com técnicas de pesquisa documento-legal e bibliográfica.

\section{CONSTRUINDO A CONCEPÇÃO DE CIDADANIA}

A partir do momento em que se resolve desenvolver um estudo sobre cidadania, deve-se ficar atento para as generalizações, que na maioria das vezes acabam esvaziando o termo e desvirtuando a sua compreensão.

Isso por que a expressão cidadania traduz um significado que não é único, mas um conceito histórico,

[...] o que significa que seu sentido varia no tempo e no espaço. É muito diferente ser cidadão na Alemanha, nos Estados Unidos ou no Brasil, não apenas pelas regras 
que definem quem é ou não titular da cidadania, mas também pelos direitos e deveres distintos que caracterizam o cidadão em cada um dos Estados nacionais. (PINSKY, 2010, p. 9)

Além disso, a ideia que a modernidade aduz à cidadania não é a mesma concebida pela antiguidade, já que cada momento histórico construiu uma percepção conforme seus fatores sociais, culturais e econômicos.

Para Burdeau, "no Estado, o Poder é institucionalizado, no sentido de ser transferido da pessoa dos governantes, que já não têm seu exercício, para o Estado, que desde então se torna seu único proprietário" (2005, p. 12).

Uma das características da cidadania antiga era o seu exercício direto, ou seja, sem o intermédio de representantes. Entretanto, em Atenas, por exemplo, tal prerrogativa não se estendia a estrangeiros, crianças, mulheres e escravos, constituindo-se de forma excludente (GUARINELLO, 2010).

Tal situação se dava porque, para exercer a cidadania, a pessoa deveria ter tempo livre que Ihe possibilitasse adquirir sabedoria e refletir sobre a sociedade, agregando bagagem para o exercício ativo enquanto cidadão (RICCl, 2014).

Em Roma, por outro lado, a cidadania foi construída e moldada nas disputas sociais entre patrícios e plebeus, por meio das quais estes últimos buscavam a plena cidadania que até então não Ihes era reconhecida (FUNARI, 2010).

Outra peculiaridade de Roma dizia respeito à possibilidade de um cidadão criar outro cidadão por meio de seu ato de vontade, com a aprovação de um magistrado, ou seja, tal ato se constituía em uma das formas, por exemplo, de tornar um escravo liberto, permitindo-Ihe fazer parte, a partir de então, da sociedade romana como cidadão (GIARDINA, 1992).

Segundo Streck e Morais (2012), na Idade Média não existiu um Estado, mas sim um conjunto fragmentado de poderes que se concentravam nos feudos, dificultando a proliferação da cidadania.

O surgimento de um poder superior, acima de todos, chamado Estado, é algo que Capella (2002) denomina projeto da modernidade. Seu nascimento ocorreu em determinado momento histórico, em consequência da alteração das forças produtivas e das relações sociais então existentes (ENGELS, 2000).

Foi a partir desse contexto que ocorreu a divisão entre o mundo privado e público; de um lado, se situava a sociedade civil, e de outro, o Estado, iniciando o "processo de despolitização da cidadania", impossibilitando a atuação do indivíduo na esfera pública, fazendo com que este não se sentisse parte da sociedade, ficando alheio e distanciado da atuação política social (VIEIRA, 2013). Cabe registrar que os teóricos do contratualismo terão papel primordial nessa concepção de surgimento do modelo estatal.

Nesse cenário de surgimento do Estado, em sua primeira concepção absoluta, com a centralização do poder nas mãos do rei, a burguesia se encontrava insatisfeita, pois também almejava o poder político, sendo que, com a acumulação de capital, acabou ocorrendo a 
possibilidade de enfrentar o monarca, fazendo-se surgir a segunda fase do Estado moderno, qual seja, a fase liberal, por meio das revoluções industrial, inglesa, americana e francesa (VIEIRA, 2013).

Esse Estado liberal que foi se constituindo em meados do século XX entendeu que os valores individuais deveriam estar acima de tudo e de todos, inclusive do próprio ente estatal, dando total liberdade para a pessoa enquanto sujeito e não enquanto sociedade pertencente da coletividade (MACEDO, 1995).

Como bem aponta Bonavides (2001, p. 40), "na doutrina do liberalismo, o Estado foi sempre o fantasma que atemorizou o indivíduo. O poder, de que não pode prescindir o ordenamento estatal, aparece, de início, na moderna teoria constitucional como maior inimigo da liberdade".

Assim sendo, o Estado liberal vai de encontro com o absoluto, pois enquanto neste último o monarca detinha o poder e o próprio povo em suas mãos, atribuindo ao aparelho estatal status de propriedade, naquele primeiro, muito pelo contrário, o indivíduo, despido de controle, deveria autogovernar-se assumindo o comando de sua vida.

Ocorre que isso acabou gerando instabilidade e um crescente índice de desigualdade social, pois, com a intervenção mínima do Estado na vida das pessoas, ocorreram violações de direitos, em especial na área laboral, culminando no surgimento de movimentos trabalhistas em prol da ampliação da atuação estatal, no desenvolvimento econômico e na inclusão de novas políticas públicas, o que fez surgir então o Estado de Bem-Estar Social (VIEIRA, 2013).

O Estado de Bem-Estar Social acabou significando o intervencionismo estatal, transformando de uma vez por todas o modelo liberal até então imposto à sociedade, fato que se destacou como importante passo, já que a burguesia foi obrigada a reconhecer os direitos do proletariado (BONAVIDES, 2001).

Entretanto, em que pesem os avanços que este Estado possa ter trazido para a sociedade no sentido de conquista de direitos até então não reconhecidos, tal fato não alterou em nada as peculiaridades relacionadas à cidadania, pois ela continuou sendo compreendida tão somente como instrumento de representação política (VIEIRA, 2010; VIEIRA, 2013; DALLARI, 2009).

Portanto, o Estado de Bem-Estar Social, por diversas razões, tanto internas, peculiares ao próprio Estado, quanto externas, desencadeadas na conjuntura internacional, começou a apresentar seus primeiros sintomas de crise, os quais irão refletir inclusive no âmbito jurídico e político da cidadania representada (GARCIA-PELAYO, 2009; POGGI, 1981).

O passo seguinte foi naturalmente a concretização do Estado Democrático de Direito, que, apesar dos obstáculos do neoliberalismo, permitiu à cidadania se constituir de um caráter tanto representativo quanto participativo, tentando resgatar a inserção da sociedade nos espaços públicos, ensejando, como bem menciona Vieira (2013, p. 153), "a coexistência de duas esferas de soberania, a estatal representativa e a coletiva participativa da sociedade".

Portanto, no Estado Democrático de Direito, ser cidadão envolve uma interpretação elástica, abrangendo tanto o direito ao voto como também a participação nas esferas sociais, contribuindo então para a construção do diálogo entre o público e o privado, alcançando-se assim a possibilidade (pelo menos formal) de acesso de todos aos espaços coletivos. 


\subsection{A cidadania no Brasil a partir da Constituição Federal de 1988}

A cidadania é definida conforme o modelo político utilizado pelo Estado. Andrade (1998) exemplifica que no liberalismo ela é ligada ao direito de representação política, e o cidadão, por consequência, nada mais é que um indivíduo detentor de direitos eleitorais, ou seja, detém tão somente a prerrogativa de votar e ser votado e de exercer cargos públicos.

Embora a fase do liberalismo tenha sido superada no País, muitos resquícios permanecem impregnados devido à cultura secular imposta à sociedade. No que diz respeito à prática da cidadania, Costa e Ritt (2014) aduzem que se faz necessária uma reestruturação, no sentido de

[...] dinamizar e pluralizar o conceito, ampliando seus limites especificamente: deslocando a cidadania para um processo que seja mobilizado pela participação política. Também deslocar a cidadania não mais como um conceito que engloba unicamente os direitos políticos, mas sim, para uma dimensão que engloba o conjunto dos Direitos Humanos.

A cidadania está em constante processo de transformação, pois, quanto maior a organização e a mobilização da sociedade e de seus atores, mais ampla será a sua definição, rompendo-se assim com o binômio votar e ser votado para assumir uma postura de efetiva participação da realidade social.

Portanto, esse caminho que está sendo construído objetiva "oportunizar o acesso igualitário ao espaço público como condição de existência e sobrevivência dos homens enquanto integrantes de uma comunidade política" (CORRÊA, 2002, p. 221), razão pela qual a CRFB/1988 seguiu esse norte.

Em seu artigo 1으, tal documento político já previu que a República Federativa do Brasil constitui-se em Estado Democrático de Direito, significando um avanço em termos de respeito aos direitos humanos e às garantias fundamentais (BRASIL, 1988).

Isso se deu devido seu conteúdo transformador da realidade,

[...] não se restringindo, como o Estado Social de Direito, a uma adaptação melhorada das condições sociais de existência. Assim, o seu conteúdo ultrapassa o aspecto material de concretização de uma vida digna ao homem e passa a agir simbolicamente como fomentador da participação pública no processo de construção e reconstrução de um projeto de sociedade, apropriando-se do caráter incerto da democracia para veicular uma perspectiva de futuro voltada à produção de uma nova sociedade, onde a questão da democracia contém e implica, necessariamente, a solução do problema das condições materiais de existência. (STRECK; MORAIS, 2012, p. 97-98)

Portanto, o Estado Democrático de Direito objetiva a inserção da lei num contexto instrumental de disponibilidade do aparelho estatal e não de uma maneira hierarquizante e coercitiva para com as pessoas, fortalecendo com isso o aspecto da cidadania.

Esse novo paradigma da cidadania configura-se em uma "nova legitimidade: o abraço com a Constituição aberta, onde, sem cidadania não se governa e sem povo não se alcança a soberania legítima" (BONAVIDES, 2008, p. 36). 
O artigo 10 da Constituição Federal de 1988 trouxe ainda dentre seus fundamentos a soberania (inc. I), cidadania (inc. II), dignidade da pessoa humana (inc. III), os valores sociais do trabalho e da livre-iniciativa (inc. IV) e o pluralismo político (inc. V), demonstrando sua preocupação com outras formas de atuação legítima para além daquela realizada pelo Estado, respeitando os direitos que são atribuídos a todo ser humano (BRASIL, 1988).

Dentre os instrumentos de democracia, o mesmo dispositivo, em seu parágrafo único, elencou três tipos, sendo eles a representativa, a semidireta e a participativa, construindo assim uma nova concepção de cidadania não limitada apenas a aspectos relativos ao direito de votar e ser votado (BRASIL, 1988).

Segundo Bastos (2002), a democracia representativa se dá mediante a vontade do povo, exteriorizada por meio de representantes, ou seja, não existe nesse modelo a participação direta, mas intermediada por outras pessoas eleitas para atuarem de tal modo.

A vontade popular então é encarada como algo forte, já que é ela quem escolhe tanto os membros do Congresso Nacional (Poder Legislativo), quanto os membros do Poder Executivo (VIEIRA, 2013), havendo um respeito pela vontade das pessoas independentemente de sua condição na sociedade.

Isso porque, mais adiante, em seu artigo 14, a Constituição Federal de 1988 estabeleceu que a "soberania popular será exercida pelo sufrágio universal e pelo voto direito e secreto, com valor igual para todos", sendo o voto obrigatório aos cidadãos maiores de 18 anos (§ 1익), e facultativo para os analfabetos ( $(10$, “a"), maiores de setenta anos ( $\S 10$, "b"), para os maiores de dezesseis e menores de dezoito anos ( $§ 10$, "b") (BRASIL, 1988).

Ao observar a exigência de filiação partidária do parágrafo $20, \mathrm{~V}$, desse mesmo dispositivo, no que tange à eleição para candidatos nas eleições proporcionais ou majoritárias, Mezzaroba (2014, p. 42) afirma que a democracia brasileira "caracteriza-se como uma democracia representativa partidária, isto é, uma democracia que não admite candidaturas avulsas, candidaturas desvinculadas das organizações político-partidárias".

$\mathrm{Na}$ democracia semidireta, por outro lado, o povo interfere, conforme artigo 14 da Constituição Federal de 1988, porém por meio do campo legislativo, ou seja, utilizando como instrumento o plebiscito (inc. I), o referendo (inc. II) e a iniciativa popular (inc. III) (BRASIL, 1988).

Além da democracia representativa e da semidireta, a CRFB/1988 dispõe também da chamada democracia participativa, que,

[...] apesar de se contrapor à representação no que diz respeito ao exercício direto da cidadania a partir das manifestações coletivas da Sociedade, o paradigma participativo não renega a existência da democracia representativa, mas apenas the retira a exclusividade como lócus do exercício da cidadania. Deste modo, teremos uma coabitação entre o paradigma moderno representativo e o paradigma participativo pós-Moderno. (VIEIRA, 2013, p. 180)

Sendo assim, a própria CRFB/1988 foi elaborada num cenário de mobilização e participação social, resultando num documento de caráter democrático, já que acolhe em seu texto a democracia representativa, semidireta e participativa enquanto instrumentos disponíveis para a sociedade.

Bonavides (2008, p. 345), ao discorrer sobre a democracia participativa, afirma que "há, portanto, que ministrar a cidadania, desde já, a lição constitucional dos preceitos que possibilitam 
e fazem exeqüível a imediata adoção da democracia participativa. Democracia que é o mais alto grau de legitimação do governo popular em nossa época".

Nesse contexto, para Vieira (2013, p. 187), a cidadania participativa foi uma conquista para o Estado Democrático de Direito, pois, "para além do estabelecimento de regras de participação política e ampliação do reconhecimento dos direitos humanos/fundamentais", garantiu que este instrumento tivesse como protagonista a própria sociedade.

Portanto, a cidadania participativa se dá como um exercício diário, ou seja, por meio do engajamento, da mobilização, da conscientização, e em especial do sentimento de fazer parte enquanto ator social.

\subsection{Cidadania participativa no Sistema Único de Assistência Social}

A cidadania participativa na assistência social se concretiza por meio do controle social; é por meio de mecanismos de fiscalização e monitoramento que a sociedade pode atuar perante todas as atividades do Estado.

O controle social se caracteriza como:

[...] instrumento de efetivação da participação popular no processo de gestão político-administrativa, financeira e técnico-operativa, com caráter democrático e descentralizado. Dentro dessa lógica, o controle do Estado é exercido pela sociedade na garantia dos direitos fundamentais e dos princípios democráticos balizados nos preceitos constitucionais. (BRASIL, 2005, p. 51)

Quando se fala em controle social, a ideia é colocar em evidência a participação da população nos assuntos que afetam sua trajetória de vida, descentralizando o poder estatal e atribuindo-o também a outros segmentos da sociedade, para que com isso se consiga avançar nas decisões de forma democrática.

Com a CRFB/1988 e posteriormente com a regulamentação da Lei Orgânica de Assistência Social (LOAS) em 1993, a assistência social configurou-se como uma política pública de caráter social, na qualidade de um direito do cidadão e dever do Estado. Resultou como conquista da sociedade, em decorrência das lutas empreendidas pelos movimentos sociais (BRASIL, 1988; BRASIL, 1993; BRASIL, 2004).

A CRFB/1988 determinou em seu artigo 203, I e II, que a assistência social será prestada a quem dela necessitar, independentemente de contribuição à seguridade social, com o propósito de dar proteção à família, à maternidade, à infância, adolescência e à velhice, bem como amparar crianças e adolescentes carentes, e a Lei Orgânica de Assistência Social positivou tais mandamentos em seu artigo 2‥ (BRASIL, 1988; BRASIL, 1993).

Com fulcro nestes dispositivos, o Ministério do Desenvolvimento Social e Combate à Fome, a Secretaria Nacional de Assistência Social e o Conselho Nacional de Assistência Social cumpriram com as deliberações da IV Conferência Nacional de Assistência Social, realizada em 2003, elaborando, aprovando e tornando pública a Política Nacional de Assistência Social, em 2004, com o objetivo de materializar as diretrizes da Lei Orgânica de Assistência Social e implantar o Sistema Único de Assistência Social (BRASIL, 2004). 


\section{O Sistema Único de Assistência Social é}

[...] uma ferramenta de gestão da Política Nacional de Assistência Social e constituise na regulação e organização, em todo o território nacional, da rede de serviços socioassistenciais, os quais têm como foco prioritário a atenção à família extensa e o território como base de organização. (THIOLLENT, 2014)

Tal Sistema é constituído pelo conjunto de serviços, programas, projetos e benefícios no âmbito de assistência social, prestados diretamente ou por meio de convênios com organizações sem fins lucrativos, por órgãos e instituições públicas federais, estaduais e municipais da administração direta e indireta e das fundações mantidas pelo poder público (YAZBEK, 2006, p. 130).

O Sistema Único de Assistência Social foi instituído num cenário de participação popular, fazendo com que o serviço social se preocupasse com a atuação da sociedade na deliberação e fiscalização das políticas socioassistenciais.

Além disso, CRFB/1988 e a LOAS organizaram as diretrizes da assistência, estando dentre elas a "participação da população na formulação das políticas no controle das ações em todos os níveis" (art. 204, II, CF/88) (BRASIL, 1988), (art. 5o, II, LOAS) (BRASIL, 1993), ou seja, ambos os regulamentos jurídicos trouxeram em seu bojo a orientação para o exercício do controle social por parte da população.

No âmbito do Sistema Único de Assistência Social, tal controle se da por meio dos conselhos e das conferências, previstos na LOAS.

Gohn entende que os conselhos se concretizam como "canais de participação que articulam representantes da população e membros do poder público estatal em práticas que dizem respeito à gestão de bens públicos" (2011, p. 7).

Segundo Raicheles,

Pela sua composição paritária entre representantes da sociedade civil e do governo, pela natureza deliberativa de suas funções e como mecanismo de controle social sobre as ações estatais, pode-se considerar que os Conselhos aparecem como um constructo institucional que se opõe a histórica tendência clientelista, patrimonialista e autoritária do Estado brasileiro ([s/d], p. 6).

Quanto às características do conselho de assistência social, cabe destacar seu caráter permanente, composição paritária entre representantes do governo e da sociedade e sua natureza deliberativa, constituído nos três níveis da administração e devendo ser criado por lei, inclusive para recebimento de recursos (art. 16, LOAS) (BRASIL, 1993).

Os conselhos de assistência social possuem ainda algumas atribuições, de acordo com a Política Nacional de Assistência Social, sendo elas

[...] a deliberação e fiscalização da política de assistência social e de seu financiamento, em consonância com as diretrizes propostas pela conferência; a aprovação do plano; apreciação e aprovação da proposta orçamentária para a área e do plano de aplicação do fundo, com a definição dos critérios de partilha dos 
recursos, exercidas em cada instância em que estão estabelecidos (BRASIL, 2005, p. 51).

Os conselhos, portanto, foram criados "para assegurar aos cidadãos organizados melhores recursos e meios de influenciar na definição da agenda pública em setores específicos de políticas sociais" (CAMPOS, 2006, p. 111-112), ou seja, estabeleceram-se enquanto ferramentas disponíveis para utilização da sociedade.

Outro mecanismo de controle na assistência social diz respeito às conferências, válidas como instrumentos de mobilização, que ocorrem de quatro em quatro anos com o escopo de "avaliar a situação da assistência social e propor diretrizes para o aperfeiçoamento do sistema" (art. 18, VI, LOAS) (BRASIL, 1993).

Elas se constituem em um espaço coletivo no qual usuários, trabalhadores, gestores e entidades que atual na área da assistência social avaliam e fazem propostas de diretrizes para a elaboração e execução da política de assistência, no âmbito do Estado brasileiro, em todas as suas esferas federativas (nacional, estadual, distrital e municipal).

Neste sentido, tais conferências se estabelecem como mecanismos de acesso da população aos espaços públicos, possibilitando com isso, a defesa dos direitos socioassistenciais e o fortalecimento do protagonismo social.

Essa preocupação resultou no processo de democratização da política socioassistencial, que caminha para a construção de um projeto de sociedade autônoma e participativa, alcançando, assim, maior legitimidade na atuação e na formulação de políticas públicas de atendimento, proteção, promoção e justiça.

\section{CONSIDERAÇÕES FINAIS}

A inserção da cidadania participativa, juntamente com a representativa e a semidireta, na CRFB/1988, possibilitou o reconhecimento do respeito aos direitos políticos, sociais e culturais, culminando como importante conquista para o Estado Democrático de Direito brasileiro.

Além disso, tal documento constitucional avançou em termos de estruturação da cidadania participativa na elaboração e no controle das políticas públicas realizadas pelo Estado, em especial a Política Nacional de Assistência Social, significando uma preocupação com a garantia de direitos.

Portanto, o Sistema Único de Assistência Social, ao utilizar-se da matriz de cidadania participativa, reconheceu a importância do controle social para o fortalecimento da política pública na área da assistência social.

Neste sentido, tanto os conselhos quanto as conferências são relevantes ferramentas de controle social na área da assistência social, necessárias para a concretização do SUAS. Entretanto, deve ser destacado que se está diante de um processo em construção, sendo necessário que a sociedade ocupe esses espaços participativos e seja protagonista dos atos decisórios, para não correr o risco de as estruturas participativas, conquistadas na trajetória de redemocratização do Brasil após o regime ditatorial militar, virem a se converter em espaços cartoriais, de cumprimento 
de requisitos meramente formais para a transferência de recursos públicos, eivados de relações patrimonialistas e clientelistas.

Por fim, cabe destacar que o controle social no âmbito da assistência social, sendo um processo em construção, somente poderá cumprir o seu papel na concretização da cidadania por meio da reinvenção quotidiana desses espaços de democracia participativa.

\section{REFERÊNCIAS}

1. ANDRADE, V. R. P. de. Cidadania, Direitos Humanos e Democracia: Reconstruindo o Conceito Liberal de Cidadania. In: SILVA, R. P. (Org.). Direitos Humanos como educação para a Justiça. São Paulo: LTr, 1998.

2. BASTOS, C. R. Curso de teoria do Estado e ciência política. 5. ed. São Paulo: Saraiva, 2002.

3. BONAVIDES, P. Do Estado liberal ao Estado social. 7. ed. rev. e ampl. São Paulo Malheiros, 2001.

4. . Teoria constitucional da democracia participativa: por um Direito Constitucional de luta e resistência - por uma nova hermenêutica - por uma repolitização da legitimidade. 3. ed. São Paulo: Malheiros, 2008.

5. BRASIL. Constituição da República Federativa do Brasil: atualizada até a Emenda Constitucional no 90, Brasília, DF, 05 de outubro de 1988. Disponível em: <http://www.planalto.gov.br/ccivil_03/Constituicao/ConstituicaoCompilado.htm>. Acesso em: 17 de dezembro de 2015-A.

6. Lei no 8.742, de 07 de dezembro de 1993. Dispõe sobre a Lei Orgânica da Assistência Social e dá outras providências. Brasília, DF. Disponível em: <http://www.planalto.gov.br/ccivil_03/Leis/L8742.htm>. Acesso em: 17 de dezembro de 2015B.

7.

. Resolução no 145, de 15 de outubro de 2004. Aprova a Política Nacional de Assistência Social. Diário Oficial da União, Brasília, DF, 26 de outubro de 2004. Disponível em: <http://www.mds.gov.br/webarquivos/legislacao/assistencia_social/resolucoes/2004/Resoluc ao\%20CNAS\%20no\%20145-\%20de\%2015\%20de\%20outubro\%20de\%202004.pdf>. Acesso em: 17 de dezembro de 2015 -C.

8. 8 . Política nacional de assistência social - PNAS/2004. Brasília, DF: Ministério do Desenvolvimento Social e Combate à Fome, 2005. Disponível em: <http://www.mds.gov.br/webarquivos/publicacao/assistencia_social/Normativas/PNAS2004.p df>. Acesso em: 17 de dezembro de 2015.

9. BuRdeAu, G. O Estado. Tradução de Maria Ermantina de Almeida Prado Galvão. São Paulo: Martins Fontes, 2005.

10. CAMPOS, E. B. Assistência social: do descontrole ao controle social. Revista Serviço Social e Sociedade, São Paulo, Cortez, n. 88, ano XXVI, jun. 2006.

11. CAPELLA, J. R. Fruto proibido: uma aproximação histórico-teórica ao estudo do Direito e do Estado. Tradução de Gresiela Nunes Rosa e Lédio Rosa de Andrade. Porto Alegre: Livraria do Advogado, 2002.

12. CORRÊA, D. A construção da cidadania: reflexões histórico-políticas. 3. ed. ljuí: Unijuí, 2002. 
13. COSTA, M. M. M. da; RITTI, C. F. Cidadania no Brasil: sua construção a partir de uma ótica humanista, voltada aos direitos humanos e a necessária superação de velhos paradigmas. Disponível em: <http://www.conpedi.org.br/manaus/arquivos/anais/bh/caroline_fockink_ ritt2.pdf>. Acesso em: 10 jul. 2014.

14. DALLARI, D. de A. Elementos de teoria geral do Estado. 28. ed. São Paulo: Saraiva, 2009.

15. ENGELS, F. A origem da família, da propriedade privada e do Estado. Tradução de Leandro Konder. 15. ed. Rio de Janeiro: Bertrand Brasil, 2000.

16. FUNARI, P. P. A cidadania entre os romanos. In: PINSKY, J.; PINSKY, C. B. (Orgs.). História da cidadania. 5. ed. São Paulo: Contexto, 2010. p. 49-80.

17. GARCIA-PELAYO, M. As transformações do Estado contemporâneo. Tradução e prefácio de Agassiz Almeida Filho. Rio de Janeiro: Forense, 2009.

18. GIARDINA, A. O homem romano. In: (Dir.). O homem romano. Tradução de Maria Jorge Vilar de Figueiredo. Lisboa: Presença, 1992. p. 7-17.

19. GOHN, M. da G. Conselhos gestores e participação sociopolítica. São Paulo: Cortez, 2011.

20. GUARINELLO, N. L. Cidades-Estado na antiguidade clássica. In: PINSKY, J.; PINSKY, C. B. (Orgs.). História da cidadania. São Paulo: Contexto, 2003. p. 29-47.

21. MACEDO, U. B. de. Liberalismo e justiça social. São Paulo: Ibrasa, 1995.

22. MEZZAROBA, O. A democracia representativa partidária brasileira: necessidade de (re)pensar o conceito de povo como ator político. Disponível em: <http://www.justicaeleitoral.jus.br/arqui vos/tre-pr-parana-eleitoral-revista-1-artigo-3-orides-mezzaroba>. Acesso em: 10 jul. 2014.

23. PINSKY, J. Introdução. In: PINSKY, J.; PINSKY, C. B. História da cidadania. 5. ed. São Paulo: Contexto, 2010. p. 9-13.

24. POGGI, G. A evolução do Estado moderno: uma introdução sociológica. Tradução de Álvaro Cabral. Rio de Janeiro: Zahar, 1981.

25. RAICHELES, R. Democratizar a gestão das políticas sociais - um desafio a ser enfrentado pela sociedade civil. Serviço Social e Saúde: formação e trabalho profissional, p. 1-17, [s/d]. Disponível em: <http://www.sbfa.org.br/fnepas/pdf/servico_social_saude/texto1-4.pdf>. Acesso em: 29 out. 2015.

26. RICCI, M. T. O ócio e a emancipação. Disponível em: <http://www.sbpcnet.org.br/livro/57ra/ programas/conf_simp/textos/mteresaricci.htm>. Acesso em: 26 jun. 2014.

27. STRECK, L. L.; MORAIS, J. L. B. de. Ciência política e teoria geral do Estado. 6. ed. Porto Alegre: Livraria do Advogado, 2012.

28. THIOLLENT, M. Sistema Único de Assistência Social: bases políticas e institucionais para o reordenamento da assistência social. Disponível em: <http://www.tj.sp.gov.br/Download/ Corregedoria/pdf/sist_unico_as.pdf>. Acesso em: 25 abr. 2014.

29. VIEIRA, Reginaldo de Souza. Partidos políticos brasileiros: das origens ao princípio da autonomia político-partidária. Criciúma: Ediunesc, 2010.

30. _ A cidadania na república participativa: pressupostos para a articulação de um novo paradigma jurídico e político para os Conselhos de Saúde. 2013. 540 fl. Tese (Doutorado em 
Direito) - Florianópolis, PPGD-UFSC, 2013.

31. YAZBEK, Maria Carmelita. A assistência social na prática profissional: história e perspectivas. Revista Serviço Social e Sociedade, São Paulo, Cortez, ano XXVI, n. 88, jun. 2006. 